\title{
THE REALIZATION OF THEMATIC PROGRESSION IN ONLINE IELTS WRITING TASK 2 SAMPLES IN AN ENGLISH-LEARNING WEBSITE: A CASE STUDY
}

\author{
Nguyen Van Thang ${ }^{1}$, Nguyen Thi Minh Tam² \\ 1. Faculty of English Language Teacher Education \\ VNU University of Languages and International Studies, Pham Van Dong, Cau Giay, Hanoi, Vietnam \\ 2. Faculty of Linguistics and Cultures of English-speaking countries \\ VNU University of Languages and International Studies, Pham Van Dong, Cau Giay, Hanoi, Vietnam
}

Received 1 July 2020

Revised 14 August 2020; Accepted 15 November 2020

\begin{abstract}
This research aims at investigating the realization of thematic progression (TP) patterns, which is defined as "the way in which the theme of a clause may pick up, or repeat a meaning from a preceding theme or rheme" (Paltrigde, 2006, p. 148), and their effects on text quality of online IELTS Writing Task 2 samples. Investigated in the light of systemic functional approach, TP is classified into five patterns, namely Simple Linear Progression (SLP), Constant Progression (CP), Split Rheme Progression (SRP), Split Theme Progression (STP) and Derived Hypertheme Progression (DHP) (McCabe, 1999). In this study, the corpus consisting of 24 sample essays derived from an English-learning website was analyzed using both quantitative and qualitative methods. The results of this study highlight that SLP is the most frequently employed pattern in the corpus, followed by CP, SRP, STP and DHP patterns respectively. The analysis also shows that proper employment of TP overall is a contributing factor to the coherence and cohesion of the text, with each pattern exerting different effects. SLP, with its cross-referential links, yields a constantly developing and cohesive text whilst CP keeps a strong thematic focus. Meanwhile, SRP and STP patterns are both found to offer a planned text development and DHP creates cohesion with hypernym-hyponym relation. Problems related to the lack of TP, inappropriate theme positioning and the overuse of the theme "It" and "There" are also reported in the corpus.
\end{abstract}

Keywords: thematic progression, sample IELTS Writing Task 2, text quality

\section{Introduction}

Since the second half of the previous century, writing as a main skill in language has received increasing attention as an emerging topic of research, according to Soleymanzadeh and Gholami (2014). Among many aspects of this skill, the notion of cohesion, theme-rheme, and thematic progression (hereafter called TP) has been a matter of great concern for language researchers and educators alike (Belmonte \& McCabe, 2001; Bloor \& Bloor, 2003; Brown \& Yule, 1983; Halliday \& Matthiessen, 2013; McCabe, 1999).

\footnotetext{
* Corresponding author. Tel.: 84-989669422, Email: tamntm1982@vnu.edu.vn
}

\section{Thematic progression}

\subsection{Theme and thematic progression}

First put forward by Mathesius of Prague School in 1939, theme-rheme is a major component in the textual metafunction of Systemic Functional Grammar. According to McCabe (1999), theme is defined in a variety of ways, for example, as "conveying the old or given information" (Babby, 1980, p. 3) or "what the sentence is about" (Witte, 1983, p. 338). However, this study adopts the definition of Halliday and Matthiessen (2013), which posits that theme is "the point 
of departure of the message" (p. 89). While this definition seems to be strictly positional, it is chosen because the point of departure indeed means more than just occupying the first position as it provides the context for the rest of the message (Halliday, 1994; Martin, 1992) and initiates "the semantic journey" (McCabe, 1999, p. 62). Rheme, meanwhile, is the "remainder of the message, the part in which the theme is developed" (Halliday \& Matthiessen, 2013, p. 89) and typically contains unfamiliar or new information (Eggins, 2004).

Concerning TP, the definition put forward by Paltridge (2006) is chosen as the working definition in the present study. In accordance with this definition, TP is "the way in which the theme of a clause may pick up, or repeat a meaning from a preceding theme or rheme" (Paltrigde, 2006, p. 148).

\subsection{Categorisation of thematic progression}

McCabe's (1999) model of TP, which is a revised version of the model by Daneš (1974), is preferred in this study. The rationale for this choice is that this classification scheme is "more plausible, attestable, and complete than the other categorizations used for analyzing theme and TP patterns in texts" (Martínez, 2003, p. 108).

Below is the definition of 5 patterns of TP proposed by McCabe (1999):

(i) Simple Linear Progression (SLP): The rheme of the previous clause becomes the theme of the following clause.

(ii) Constant Progression (CP): The theme of the previous clause is the same as the theme of the following clause.

(iii) Split Rheme Progression (SRP): The rheme of a clause contains two or more ideas that are picked up in following clauses.

(iv) Split Theme Progression (STP): The theme of a clause is composed of two or more items, each of which is considered a theme in the following clause.

(v) Derived Hypertheme Progression (DHP): The themes in following clauses are derived from a hypertheme in the previous clause.

\section{Thematic progression and text quality}

The majority of studies in the current body of research concur regarding the significant role of TP in text quality, particularly in terms of cohesion and coherence. In fact, TP is a major aspect of "how speakers construct their messages in a way which makes them fit smoothly into the unfolding language event" (Thompson, 2013, p. 145) and it "propels the text to develop forward and provide continuity in discourse" (Kang, 2016, p. 1). As a result, writings that employ TP patterns appropriately are likely to be marked higher. For example, Wang (2007), which researches the use of TP in low-, middle- and high-scoring essays of students, finds out that the two latter groups employ more TP patterns than the former. It is also highlighted in the current literature that each pattern is realized at different frequencies and exerts different effects on text quality.

SLP is realized with a high proportion, according to Hawes and Thomas (1997), Jalilifar (2010), Nwogu and Bloor (1991), Soleymanzadeh and Gholami (2014). This pattern is also the dominant one in argumentative essays (Ebrahimi \& Khedri, 2012; Yang, 2015). In IELTS Writing Task 2 particularly, SLP is mostly realized in the body section to develop the topic presented in the topic sentence (Jalilifar, 2010; McCabe, 1999). Such a high proportion of SLP can be 
attributed to its cross-referential links from the rheme of a clause to the theme of the next one, which yields a cohesive text flow (Hawes, 2015; Eggins, 2004; McCabe, 1999). Besides, since the theme is constantly derived from the previous rheme, this pattern gives the text "a sense of cumulative development" (Eggins, 2004, p. 325). This, in turn, ensures easier tracking of idea development because readers are more aware of the source of information as well as its projected trajectory (Ebrahimi \& Khedri, 2012).

The proportion of $\mathrm{CP}$ is lower in comparison to SLP, according to the majority of research. One particular point reiterated by many studies is the ratio between SLP and CP. Generally, it is agreed that the bigger this ratio is, the better an essay will be "according to argumentative essay writing norms" (Soleymanzadeh \& Gholami, 2014, p. 3). This pattern offers a strong thematic focus and avoids going off-topic, according to Eggins (2004), McCabe (1999) and Nwogu (1991). In addition, Nwogu (1991) claims that with a fixed point of departure, readers are able to pay more attention to the new information in the rheme. However, a number of studies also caution against the overuse of $\mathrm{CP}$ (McCabe, 1999; Mellos, 2011; Wei, 2016), which may create a repetitive and stagnant text flow.

Meanwhile, the majority of findings highlight that SRP receives little attention and is not realized frequently in texts. For example, Jalilifar (2010) finds that SRP only accounts for $1 \%$ to $2 \%$ in the surveyed writing of university students while according to Soleymanzadeh and Gholami (2014), in argumentative IELTS essays, $3.02 \%$ of TP occurrences is found in this pattern. SRP is stated to outline a list of ideas for further development in the texts. In other words, this pattern provides the "underlying organizing principle for a text" (Eggins, 2004, p. 326). This pattern is also noted to be beneficial for the readers in that it provides a clear layout for them to expect and catch what the passage is about (Jalilifar, 2010).

STP, similarly, is found to be much less common than the others, with frequencies in essays recorded to range from less than $1 \%$ in Wei (2016) to approximately 4\% in Babaii et al. (2016), Jalilifar (2010), Ebrahimi and Khedri (2011). The reason for such low frequency is that this pattern positions new information in the theme, which does not follow the conventional Given-to-New approach preferred by writers, as highlighted by many studies, for example Yang (2015). Regarding its contribution to text quality, Wei (2016, p. 41) notes that STP in general is "expository in character" as it offers a list of related information to expand on the main point. Given this function, it is regarded as a means of content organization to "scaffold the content of longer stretch of texts" (Wei, 2016, p. 82).

Lastly, DHP is generally found to be of limited frequency (Hawes, 2015; Soleymanzadeh \& Gholami, 2014; Yang, 2015). These studies attribute such a low frequency to the entailed academic and specialized knowledge. However, Zhang and Li (2009) discover that DHP can be found regularly in expository and argumentative essays while Nwogu and Bloor (1991) claim that academic writings are also reported to contain a high proportion of this pattern. DHP contributes to text coherence and cohesion on the grounds that it reminds the readers of the main overarching topic and therefore keeps them focused as they need to make a connection between the hypertheme and the derived themes that follow (Hawes, 2015). 
This study also highlights that this pattern creates an academic nature given the relatively high level of shared specialized knowledge. However, many researchers have noted the difficulties in identifying this pattern due to the requirement for common specialist knowledge (McCabe, 1999; Nwogu, 1991).

\section{Thematic progression and writing performance}

As mentioned above, TP plays an important role in text cohesion and coherence as it first "enhances connectivity between ideas" and second "guides the readers through the logical paths constructed by the writers" (Ebrahimi \& Ebrahimi, 2014). In the same vein, in IELTS Writing Task 2, Soleymanzadeh and Gholami (2014) find that besides morphological, lexical and syntactic aspects, progression is one requirement of cohesion and coherence, which are two elements constituting text quality (Pitler \& Nenkova, 2008). Given such essential roles, the study of theme and TP is worthwhile as it analyses the contributing factors to the making of a text (Rørvik, 2003). Besides, writing samples are an intriguing source for analysis since they are considered references for students. Accordingly, the analysis of TP in writing samples can highlight certain features related to TP choices that can influence and be adopted in students' writings.

Despite their significance, much research has alluded to the lack of attention to TP in writing generally and in IELTS Task 2 particularly. Soleymanzadeh and Gholami (2014), Wei (2016) and Yang (2015) clearly state that too much emphasis is placed on errors below sentence level such as spelling, vocabulary or subject-verb agreement while coherent discourse organization, including TP, has been largely neglected. For example,
Ebrahimi and Ebrahimi (2014) note that the majority of IELTS examiners tend to focus on the former, while only about $30 \%$ of them pay attention to logical progression when marking. Such insufficient focus on TP is considered as a contributing factor to problems related to text organization, particularly the "loosely related events or facts, lack of a focus or central idea" (Wei, 2016, p. 1).

One further point accounting for the necessity of conducting this study is that this aspect in IELTS Task 2 is under-researched. In the current literature, the first line of study into this aspect focuses on the analysis of TP in students' writing, some of which also investigate the correlation between TP and the marking (Ebrahimi \& Khedri, 2012; Rakhman, 2013; Yang, 2015). Another field of interest is the instruction of TP for better application in writing, which has been carried out by Nurdianingsih and Purnama (2017), Purnomo (2014) and Yang (2008). Other studies also investigate the use of TP in other genres apart from students' writings, most commonly articles (Babaii et al., 2016; Jalilifar, 2010; Martínez, 2003). However, TP-related studies into IELTS Writing Task 2 are limited. According to Ebrahimi and Ebrahimi (2014), most research to date has been conducted into the role of argument in IELTS writing and the washback effects of IELTS tests on the education systems and societies in which they operate while the linguistic feature in the writing section has been largely overlooked, except for the research by Ebrahimi and Ebrahimi (2014), Nguyen and Nguyen (2018), Soleymanzadeh and Gholami (2014). Nevertheless, the former is concerned with the correlation between the scoring of IELTS Writing Task 2 and TP patterns while the corpora of the latter two 
studies consist of samples from published books rather than online sources.

Such gaps in the current body of research well justify the necessity of investigating TP in online IELTS Writing Task 2 samples.

\section{The present study}

\subsection{Scope of research}

The corpus in this study consists of 24 IELTS Writing Task 2 Samples taken from an IELTS Website with 407.000 followers on Facebook Fanpage and 217.000 followers in its group as of September 2019.

IELTS, which stands for International English Language Testing System, is among the few English language proficiency tests that measure four main language skills, namely speaking, reading, listening, and writing (Soleymanzadeh \& Gholami, 2014). In the scope of this research, Writing Task 2 (Academic Module) is studied given that TP is an important sub-criterion in coherence and cohesion, which contributes to the making and band score of a composition. Furthermore, this task receives heavier weighting compared to Task 1 and greater attention from teachers as well as learners (Ebrahimi \& Ebrahimi, 2014).

The chosen writings are stated to be samples of the actual tests from January 2019 to September 2019. There are some genres of IELTS Writing Task 2; however, given the time constraint, the scope of this study is limited to three, namely Argumentative, Discussion and Cause - Problem - Solution.

The total number of sample essays available on the website is 28 , consisting of (1) Argumentative essays - 12 samples, (2) Discussion essays - 8 samples and (3) Cause - Effect - Solution - 8 samples. In order to achieve the same number for Argumentative genre, systematic sampling was applied. Firstly, all essays of this genre were randomly numbered from 1 to 12 . Subsequently, the $3^{\text {rd }}$, $6^{\text {th }}, 9^{\text {th }}$ and $12^{\text {th }}$ essays were removed, leaving 8 essays for the corpus.

\subsection{Research aims and research questions}

To realize the overarching aim of investigating the realization of TP of Online IELTS Writing Task 2 Samples, two research objectives are set out, namely (i) exploring the realization of Themes and TP in Online IELTS Writing Task 2 Samples and (ii) investigating the potential impacts of such realization on text quality.

In accordance with these aim and objectives, the two research questions of this study are:

- What is the realization of TP in Online IELTS Writing Task 2 Samples?

- What are the potential impacts that such realization has on the texts?

\subsection{Research methods}

In order to answer the two research questions, both quantitative and qualitative methods are employed. First, the percentage of different patterns of TP was calculated using quantitative method. Subsequently, a more indepth textual analysis was conducted to find out the effects of different TP patterns on essay organization with the consideration of genre.

\subsection{Analytical framework}

This study employs McCabe's (1999) model of TP, which proposes five patterns. This model is illustrated by the following figure: 


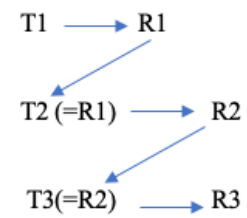

1. Simple Linear Progression

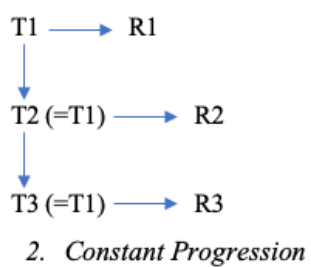

2. Constant Progression

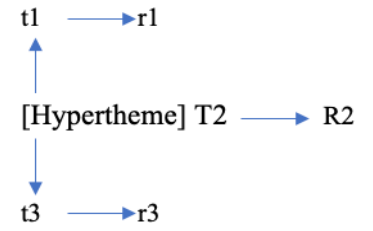

3. Derived Hypertheme Progression

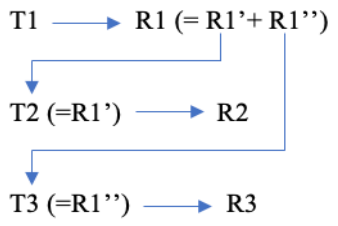

4. Split Rheme Progression

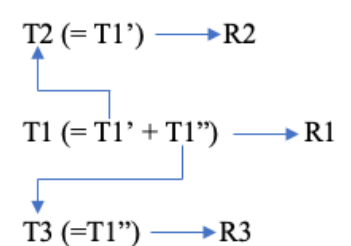

5. Split Theme Progression

Figure 1: Analytical Framework of TP patterns

The analysis unit in this study is "T-unit", which consists of "an independent clause together with all hypotactically related clauses and words that are dependent on that independent clause" (Fries, 1995, p. 49). If a dependent clause precedes an independent one, the former is taken as the theme while the latter functions as the rheme. Meanwhile, when the independent clause comes first, the theme of that clause functions as the theme for the whole clause complex. Lastly, if a sentence has more than one independent clause, it follows that there will be two T-units consisting of theme and rheme of their own. T-unit analysis, according to many studies, is viewed as the most useful unit for analyzing themes in a text (Jalilifar, 2010; Nguyen \& Nguyen, 2018).

\subsection{Data analysis procedure}

Data analysis, which is based on two analytical frameworks, including model of thematicity of Halliday and Matthiessen (2013) and McCabe's (1999) model of TP patterns, consists of two major phases as follows:

\section{a. Phase 1: Theme and TP identification and categorization}

In this phase, the analysis of data went through the following steps:

1) In each essay, "T-units" were identified.

2) Within each T-unit, the boundary between theme and rheme was drawn in accordance with Halliday's (2014) model of thematicity.

3) A diagram illustrating TP patterns of each essay was drawn.

4) From this diagram, the total numbers of all TP and each pattern were counted.

5) These numbers were also converted into percentage terms.

6) The statistics were subsequently tabulated.

\section{b. Phase 2: Effects of TP choice on texts}

In this phase, two more steps, the data analysis process was continued further with two more steps, which were:

7) Based on the diagrams from the previous stages, interpretation of the effects of TP on the coherence and cohesion of the texts was attempted along with the analysis of examples from the corpus.

8) The relation between the use of TP and genres was then drawn, followed by the comparison with other studies to examine 
the similarity and deviation compared to the existing literature.

\section{Findings and discussion}

\subsection{Answer to research question 1}

Table 1: Occurrence of TP patterns in the corpus

\begin{tabular}{ccccccc}
\hline Pattern & SLP & CP & SRP & STP & DHP & Sum \\
\hline Total & 64 & 40 & 36 & 5 & 5 & 150 \\
\hline$\%$ & 42.7 & 26.7 & 24.0 & 3.3 & 3.3 & 100 \\
\hline
\end{tabular}

Concerning the figures for separate TP patterns, it is found that SLP makes up the most significant proportion at $42.7 \%$ with 64 patterns. The second position is occupied by $\mathrm{CP}$ whose percentage is reported to be $26.7 \%$, followed closely by that of SRP (24.0\%). Meanwhile, DHP and STP share comparable figures with merely $3.3 \%$ each. This order of frequency is similar to many studies in the existing body of literature (Babaii et al., 2016; Jalilifar, 2010; Nguyen \& Nguyen, 2018; Wei, 2016). However, one notable finding emerging from the analysis is that the frequency of SRP is found in this study much surpasses other studies (Ebrahimi \& Khedri, 2012; Jalilifar, 2010; Soleymanzadeh \& Gholami, 2014; Wei, 2016).

In terms of the realization of specific patterns, SLP has the highest frequency in most of the texts except for texts 7,19 and 20. It is significant that in certain texts such as 1, 2 and 6, its proportion far exceeds others, for example $71.4 \%$ in text 6 , which is roughly five times as high as the figures for $\mathrm{CP}$ and SRP. Such a high proportion accords with the findings of most studies, for example Babaii et al. (2016), Hawes (2015) and Wei (2016). Intriguingly, the analysis of sample IELTS essays in Nguyen and Nguyen (2018) shows a strikingly similar proportion of this pattern (46.6\%), possibly due to the similarity in the corpus. The analysis also demonstrates that this pattern is mostly realized in the
There are a total of $150 \mathrm{TP}$ occurrences out of 3054 T-units in the 24 surveyed texts. Specific proportions of each TP pattern's realization are summarized in the following table. body part of the essays, which is coherent with the claim by Jalilifar (2010) that the writer uses SLP to unfold and develop the central ideas presented in the topic sentence of each paragraph. Concerning genre-based frequency, Argumentative texts employ SLP the most at $51.9 \%$. This dominant frequency in Argumentative is similar to the findings of other studies, for example, Ebrahimi and Khedri (2012), Rakhman (2013), Soleymanzadeh and Gholami (2014). SLP is also popular in the genre of Cause - Problem - Solution with the mean frequency of $35 \%$ since its realization is claimed to establish chains of relationship effective in implying causality (Jalilifar, 2010; McCabe, 1999).

$\mathrm{CP}$ is the second most frequently used pattern at over one-fourth of the total and the majority of texts employ this pattern in at least two different parts. Similar results can also be found in the studies by Babaii et al. (2016), Jalilifar (2010), and Ebrahimi and Khedri (2011). One notable finding that conforms to the existing literature is related to the ratio between SLP and CP in Argumentative essays. On average, the ratio between these two patterns is over 2:1 (48.45:21.1\%). Some argumentative texts, in particular texts 1 and 6 are found to have significantly higher ratios, which are 4:0 and 5:1, respectively. Contrary to many studies such as Mellos (2011), Wei (2016) and McCabe (1999), the problem of overusing $\mathrm{CP}$ that produces repetitive and developmentlacking discourse does not emerge from data 
analysis. Instead, most of the texts employ CP as the one and only TP pattern for the purpose of highlighting the themes and offering a central focus without necessarily rendering them simplistic and monotonous.

The frequency of SRP mostly ranges from $14 \%$ to $33 \%$, which is quite stable compared to others. Notably, statistical analysis shows that its frequency in this study far exceeds those in other studies (Ebrahimi \& Khedri, 2012; Jalilifar, 2010; Soleymanzadeh \& Gholami, 2014; Wei, 2016). Concerning genre-based frequency, this pattern is most frequently in the genre of Cause - Problem Solution texts, averaging at $34.2 \%$ and nearly doubling the Argumentative genre at 18.4\% . These predominant figures in Cause - Problem - Solution texts can be justified by the fact that this pattern lends itself to the listing of ideas in the topic sentence, in this case the list of causes, problems or solutions.

The frequency of STP is reported to be insignificant and it is absent from virtually all texts, except for texts 18, 20, 21 and 22, in which this pattern only appears once. Such low frequency does not deviate from the findings of other studies in the current body of literature (Wei, 2016; Babaii et al., 2016; Jalilifar, 2010). This is because this pattern introduces the new information at the beginning, which goes against the conventional "Given-to-New" approach and thus is not preferred despite having a similar role in idea presentation and organization compared to SRP (Yang, 2015). Interestingly, this progression pattern is only found in Cause - Problem - Solution genre in order to list the causes, effects and solutions related to a certain phenomenon discussed in the essay, as corroborated by Nurdianingsih and Purnama (2017) and Rosa and Padang (2007).

Similar to the low frequency of STP, DHP progression is only realized in 3.3\% of all clauses in the corpus. Only four texts 8 , 15,16 and 22 are reported to use this pattern, whose numbers only narrowly range from 1 to 2 patterns. This low frequency of DHP can be corroborated by the results of Soleymanzadeh and Gholami (2014) whose aim is to explore the relationship between the employment of TP in IELTS Writing Task 2 and the score. Such similarity is owing to the closer resemblance in the corpora of two studies, which are both sample IELTS Task 2 writings.

\subsection{Answer to research question 2}

The analysis highlights that each TP pattern yields different effects on text quality.

\subsubsection{Simple linear progression}

It emerges from textual analysis that this TP pattern is conducive to a closely linked and progressively developing paragraph, as in the following extract from text 10 .

\begin{tabular}{|l|ll|}
\hline 8. On the other hand, it is also essential to have a sense of the past, including & \\
family history. \\
9. This sense of history enables people to understand the socioeconomic \\
changes taking place through time.
\end{tabular}

Figure 2: The mapping of SLP pattern in Text 10 (T-units 8-12)

R8 "family history" is picked up on by the following T9 "this sense of history" with an anaphoric referent "this", forming a close connection between the two sentences and making the flow of ideas smoother and more cohesive. T10 "they" then follows the 
R9 "people" from the previous sentence, and similarly, R10 "studying their family history" is continued by "discovering the origins, the occupations and some of the life stories of previous generations of family members". It is clear that such continuous concatenation of themes and rhemes yields a continuous thread of ideas and propels the text forward, from "socioeconomic changes" (R9) to "understanding of time and place" and "a sense of belonging to their family" (R11).

The above analysis demonstrates that thanks to the cross-referential links between the rheme of one clause to the theme of the following one, SLP lends an "aura of sequence" (Hawes, 2015, p. 97) to text development, possibly rendering it more coherent (Christie \& Dreyfus, 2007; Eggins, 2004; Schleppegrell, 2004; Wang, 2007). This feature also makes it easier for the readers to trace back the points of departure as well as the course that the text is taking. Furthermore, this pattern also offers a dynamic effect in which the ideas in the text are constantly expanded so that the argument is constantly built on, thus consolidating its conviction. Notably, despite offering a constantly developing theme-rheme system, the text's main topic does not digress in that all the clauses in the texts revolve around the main theme stated in the topic sentence. All these factors related to the use of SLP may improve the text's quality. Indeed, the existing literature unanimously agrees that the high frequency of this pattern is often used by skilled writers and is indicative of higher score in the texts (Rakhman, 2013) and particularly in IELTS Writing Task 2 (Jalilifar, 2010).

\subsubsection{Constant progression}

The following analysis illustrates the realization of $\mathrm{CP}$ in text 7 .

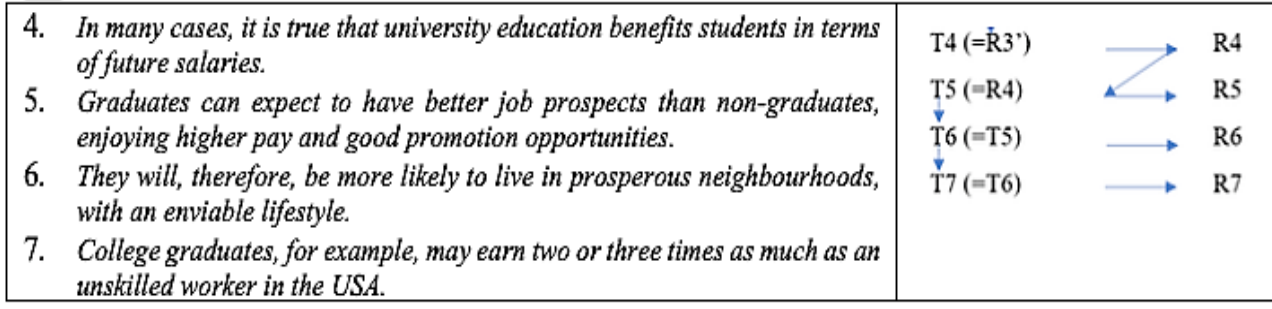

Figure 3: The mapping of CP pattern in Text 7 (T-units 4-7)

As can be seen from the extract, T5, T6 and $\mathrm{T} 7$ all refer to the subject "Graduates" while the following rhemes underline the positive effects of tertiary education, for example, "higher pay and good promotion opportunities" (R5), "to live in prosperous neighbourhoods, with an enviable lifestyle" (R6) or "earn two or three times as much as an unskilled worker in the USA" (R7). With "Graduates" and the anaphoric reference "they" positioned at the beginning of three sentences, it offers a clear and strong thematic focus to avoid topic digression. More importantly, as the themes remain static, readers' attention is also more likely to be paid to the newly introduced information in the rhemes (Nwogu, 1991), in this case the benefits of tertiary education. Since these pieces of information are central to the argument, the writer has achieved his/her aim in cementing the presented argument, thereby improving text quality.

\subsubsection{Split rheme progression}

Textual analysis of the corpus shows that the employment of SRP in topic sentences plays a vital role in the logical and coherent organization of the text, for example in text 19. 


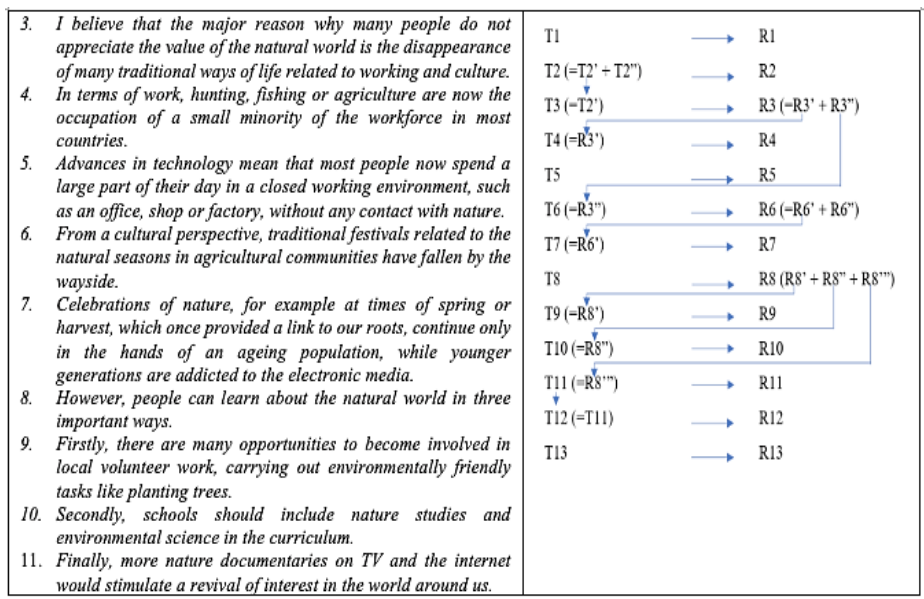

Figure 4: The mapping of SRP pattern in Text 19 (T-units 3-13)

As can be seen from T-units 3-13 of text 19, R3, which introduces the reasons for the disregard of the natural world, refers to the "disappearance of many ways of life related to working and culture". The use of phrases "related to working and culture" prepares the readers for $\mathrm{T} 4$ and $\mathrm{T} 6$, which then elaborate on these two sub-ideas. Furthermore, R8 once again uses this pattern to outline the ways in which people can gain a deeper understanding of the natural world, divided into "three important ways". This idea is then discussed in detail in the following smaller consecutive theme-rheme systems, accompanied by conjunctive adjuncts, namely "Firstly", "Secondly" and "Finally". Such a combination of appropriate textual theme choice and TP, which is frequently found in the corpus, makes the text appear to the readers as well-organized and easy to follow since the controlling ideas are scaffolded into smaller ones that continuously follow each other. Also, this way of organizing ideas adds conviction to the argument because the three following themes all support the idea presented in the topic sentence. This finding lends support to the claim by Eggins (2004) that this pattern provides the "underlying organizing principle of a text" (p. 326).

\subsubsection{Split theme progression}

STP is shown to have the same effects on text quality as SRP, as is illustrated by T-units 9-15 of text 9:

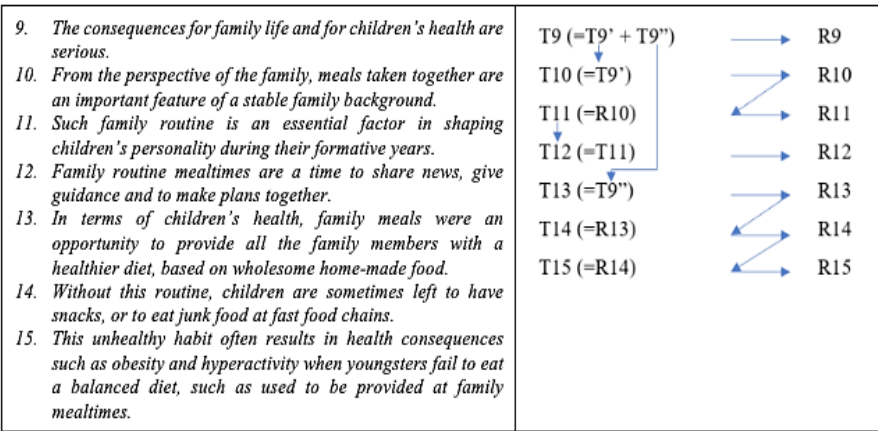

Figure 5: The mapping of STP pattern in Text 9 (T-units 9-15) 
T9 "The consequences for family life and for children's health" in the topic sentence of paragraph 2 belongs to STP pattern with two smaller themes - the effects on family and children's well-being. This theme is then expounded upon in T10 "From the perspective of the family" and T13 "In terms of children's health" along with the use of CP and SLP in order to clearly and coherently present the main arguments. Following these themes are the rhemes expounding on the important role of family meals in "shaping children's personality during their formative years" (R11) and the negative ramifications hypotheme relationship as in text 8 . due to the absence thereof such as "obesity and hyperactivity" (R15). Indeed, similar to SRP, the employment of STP in this topic sentence, accompanied by the use of SLP and $\mathrm{CP}$, "scaffolds the content of longer stretch of texts" (Wei, 2016, p. 82) in that it offers a planned development of ideas and thus effectively assists the readers in grasping an overview of the paragraph. Accordingly, text coherence and cohesion are enhanced.

\subsubsection{Derived hypertheme progression}

The analysis shows that DHT contributes to text quality thanks to the hypertheme-

\begin{tabular}{l|ll}
\hline $\begin{array}{l}\text { 12. Secondly, when individuals can put up buildings to any design } \\
\text { which they want, the result is that the city simply becomes an } \\
\text { eyesore. }\end{array}$ & $\begin{array}{l}\mathrm{T} 12\left(=\mathrm{R} 8^{\prime \prime}\right) \\
\mathrm{T} 13\left(\mathrm{~T} 13^{\prime}+\mathrm{T} 13^{\prime \prime}\right)\end{array}$ & $\rightarrow \mathrm{R} 12$ \\
$\begin{array}{l}\text { 13. Buildings may simply not blend in with each other. } \\
\text { 14. For instance, towering skyscrapers may be constructed next to } \\
\text { famous landmarks, completely overshadowing them. }\end{array}$ & $\mathrm{T} 14\left(=\mathrm{T} 13^{\prime}\right)$ \\
\end{tabular}

Figure 6: The mapping of DHP pattern in Text 8 (T-units 12-14)
As can be seen, T13 is "buildings", which in its own definition, encompasses a wide range of types. This overriding theme is then followed by a subordinate T14 "towering skyscrapers" and even in R14 "famous landmarks". Despite a lack of reiteration or anaphoric referent as in $\mathrm{CP}$, this DHP progression facilitates cohesion and coherence in that there exists a hierarchical relation between the two themes. The use of DHP in the texts, despite its limited number, is a factor in enhancing text quality. Firstly, due to the close relationship between the hyperthemes and hypothemes, the connection drawing on hierarchical order between the clauses are strengthened. Furthermore, as Eggins (2004) and Emilia (2005) have noted, this pattern provides a planned method of text development in the sense that the ideas come from a broader definition to more specific ones in the following sentences. On the part of the readers, according to Eggins (2004), Emilia (2005) and Hawes (2015), this pattern can remind them of the main topic, thus sustaining their focus on the ideas. Furthermore, as specialized knowledge is characteristic of this DHP, an academic sense is added to the texts, partially fulfilling the requirements of the Academic Module, as reiterated by Hawes (2015) and Zhang and Li (2009).

\subsubsection{Problems related to thematic} progressions

Data analysis also reveals three emerging issues related to the use of TP in the corpus. Firstly, in some texts, the lack of TP proves problematic, for instance in the extract from text 10: 


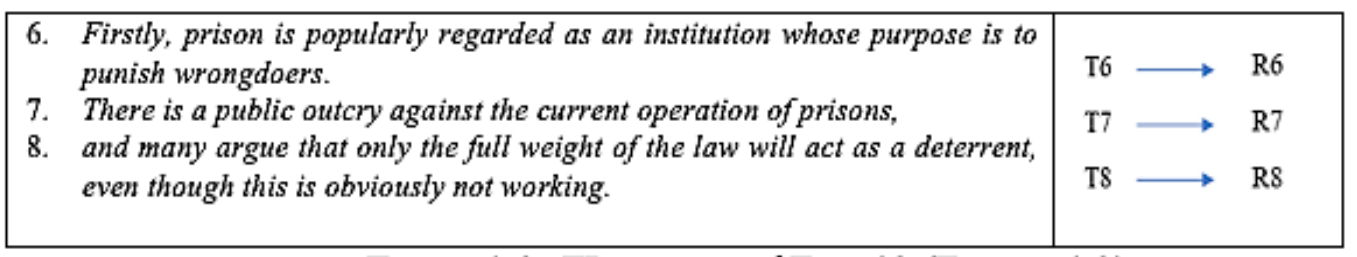

Figure 7: The mapping of TP pattern in Text 10 (T-units 6-8)

The previous extract comes from paragraph 1 of text 20. As can be seen from the extract, there exists no link between either T6 "prison" or R6 "is popularly regarded as an institution whose purpose is to punish wrongdoers" and T7 "There". Such dearth of thematicallyrelated connection may give the readers a feeling of incoherence and even digression. The same mismatch applies to the following themes and rhemes, for example between T7 "There", R7 "the current operation of prisons" and T8 "the full weight of the law". Obviously, such lack of TP potentially leads to problematic text development in which the ideas do not follow and are incoherently linked to each other, lowering its argumentation quality. Moreover, readers might encounter difficulties in following the thread of ideas put forward in the texts and identifying the points of departure in each sentence, thus being left with perplexity.

Another issue related to TP is the inappropriate theme choice and positioning, leading to a loosely developed text flow. This problem is found in T-units 5-7 of text 14 and T-units 3-5 of text 9 and T-units 4-6 of text 12. This will be illustrated in the following analysis of text 9 .

\begin{tabular}{|l|ll|}
\hline 3. On the one hand, there is an outcry in many countries over the cruel & \\
conditions in which animals are kept in some zoos. & $\mathrm{T} 3$ & \\
4. As a result, many people argue that the public must exert pressure on & $\mathrm{T} 4$ & $\mathrm{R} 3$ \\
$\begin{array}{l}\text { governments to shut down all zoos. } \\
\text { For example, in some zoos the animals are still kept in cages, with } \\
\text { little room in which to move around. }\end{array}$ & $\mathrm{T5}$ & \\
\hline
\end{tabular}

Figure 8: The mapping of TP pattern in Text 9 (T-units 3-5)

R3 from text 9 concerns the inhumane condition from which zoo animals have to suffer. In order to create cohesive text development, this rheme is supposed to be followed by a theme-rheme that elaborates on such conditions to add conviction to the argument. However, T4 and R4 mention the imperativeness for the government to "exert pressure" to close the zoos. In the meantime, T5 and R5 then incoherently delineate the specific circumstances of zoo animals, which should otherwise have taken the place of T4 and R4 to maintain a coherent thread of argument. As can be seen, the illogical arrangement of theme-rheme system in the above-given part contributes to a loose and incoherent text flow, at the same time creating a sense of confusion among readers. This inappropriate TP employment may to some extent lower the argumentation quality of the text as well.

Lastly, two themes "There" and "It" are found to be overused in certain texts, for example, in text 20 : 


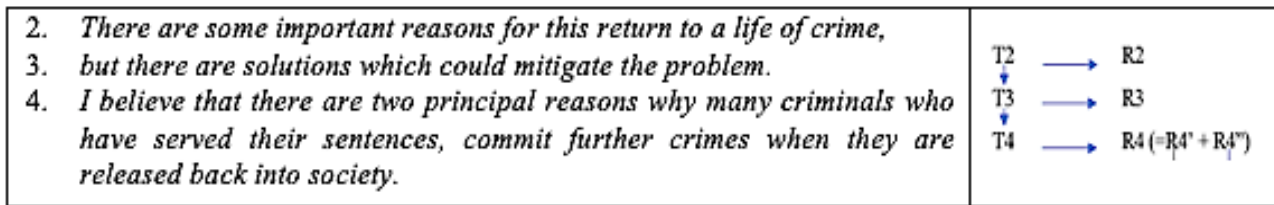

Figure 9: The mapping of TP pattern in Text 20 (T-units 2-4)

As can be seen from the excerpt, all the Topical Themes are "There”. Despite having the same theme "There" in three consecutive clauses, text development in this part is problematic since this non-referential theme cannot serve as a focal point of departure for the readers to refer to when following text development while the central information is placed in the rheme (Mauranen, 1999). Since each theme is not related to either the theme or rheme of the previous sentence, it gives the readers a repetitive and incoherent sense. Such lack of coherent and cohesive flow progression due to the overuse of "There" and " $I t$ " as themes is also found by other studies, for example Wang (2007).

\section{Conclusion}

\subsection{Summary of the findings}

With regard to the distribution of thematic progression patterns in texts, SLP is the most prevalent among the five. The second position belongs to CP, closely followed by SRP while DHP and STP are a mere minority. SLP is preferred, particularly in Argumentative and Cause - Problem - Solution genres, given its cross-referential links between clauses, hence a sense of text development and causality relation. The use of CP is ascribed to its strong thematic focus whereas SRP, which is found only in Cause - Problem - Solution genre, potentially offers a planned development of the text. Despite its minor proportion due to specialized nature, DHP can be a contributor to text cohesion of the text with its hypernym-hyponym relation. Meanwhile,
STP is not frequently realized as it contradicts the conventional "Given-to-New" principle in spite of its similar effects on text quality compared to SRP. From these aforementioned points, it can be claimed that the findings of this study corroborate the supposition of Fries (1983) that there are correlations between TP and genres as different TP patterns are frequent in different genres than others.

While the issue of overusing CP is not found as in other studies, such problems as lack of TP, inappropriate theme position as well as the overuse of themes "There" or "It" are reported from the corpus, which to a certain extent affects text cohesion and coherence.

\subsection{Implications}

The findings of this study on Thematic Progression in Online IELTS Writing Task 2 Samples may be of some assistance for pedagogical and research purposes. Specifically, teachers can draw on these findings to integrate this aspect into writing lessons and in comment sessions in order to raise students' awareness about this linguistic tool. Equipped with the knowledge about TP's employment, students are expected to be more conscious of applying this aspect into their own English writings to improve text quality, which may effectively address the issue of loosely related and incoherent texts partly caused by TP-related issues. Moreover, when properly imbedded with TP, the English writings of Vietnamese students and also other students who are nonnative to English can also appear to be more naturally 
genre-appropriate given the fact that English is a theme-inclined language. Finally, despite its limited generalizability, this study can contribute to the field of Functional Grammar and its results may provide some useful background and starting point for linguists and researchers to delve further into this topic.

\subsection{Limitations and suggestions for further studies}

\subsubsection{Limitations}

Despite the best efforts made by the researcher, some of the limitations should be acknowledged. Firstly, due to time constraints, the corpus was rather limited in terms of both quantity of texts and range of genres covered, thus restricting the results' generalizability regarding the effects and correlation between TP patterns and genres. Furthermore, the analysis may bear some weaknesses as the process of analysis can be challenging. Indeed, Nwogu (1991) and McCabe (1999) have pointed out that DHP requires specialized knowledge in certain areas, hence potential oversights. Lastly, due to the limited word count, some of the aspects of the findings may not be deeply analyzed, leaving some of the points insufficiently discussed.

\subsubsection{Suggestions for further studies}

In light of the restraints mentioned above, some following recommendations could be taken into consideration by the future researchers of this topic. Firstly, it is suggested that further research should be conducted on a larger scale with the full range of IELTS writing genres being the subject of investigation to enhance the generalizability of the results. Moreover, the results can also be analyzed to a deeper extent in order to explore other aspects yet to be sufficiently touched on in this study, for example the culturally related reasons or the influence of L1 behind TP choice.

\section{References}

Babaii, E., Atai, M. R., \& Shoja, L. (2016). A comparison of thematic choices and thematic progression patterns in the research articles of well-established and emerging disciplines. Iranian Journal of Applied Linguistics, 19(2), 33-60. https://doi.org/10.29252/ ijal.19.2.33

Babby, L. H., \& Comrie, B. (1980). Existential sentences and negation in Russian. Ann Arbor, MI: Karoma.

Belmonte, I. A., \& McCabe, A. (1998). Theme-rheme patterns in L2 writing. Didáctica, 10, 13-31.

Bloor, T., \& Bloor, M. (2013). The functional analysis of English: A Hallidayan approach. London: Routledge.

Brown, G., \& Yule, G. (1983). Discourse analysis. Cambridge: Cambridge University Press.

Christie, F., \& Dreyfus, S. (2007). Letting the secret out: Successful writing in secondary English. The Australian Journal of Language and Literacy, 30(3), 235-247.

Daneš, F. (1974). Functional sentence perspective and the organisation of the text. In F. Daneš (Ed.), Papers on functional sentence perspective (pp. 106-128). Prague: Academia.

Ebrahimi, S. F., \& Ebrahimi, S. J. (2014). Thematic progression patterns in the IELTS task 2 writing. Journal of Advances in Linguistics, 3(3), 253-258.

Ebrahimi, S. F., \& Khedri, M. (2011). Thematicity in research article abstracts: A cross-disciplinary study. Educational Quest-An International Journal of Education and Applied Social Sciences, 2(3), 287292.

Ebrahimi, S. F., \& Khedri, M. (2012). The essence of thematic structures in the academic translated texts. Journal of Education and Practice, 3(1), 3743.

Eggins, S. (2004). Introduction to systemic functional linguistics. London: Continuum.

Emilia, E. (2005). A critical genre-based approach to teaching academic writing in a tertiary EFL context in Indonesia. Doctoral dissertation, University of Melbourne.

Fries, P. H. (1983). On the status of theme in English: Arguments from discourse. In J. S. Petöfi \& E. Sözer (Eds.), Micro and macro connexity of texts (pp. 116152). Hamburg: Buske.

Fries, P. H. (1995). A personal view of theme. In M. Ghadessy (Ed.), Thematic development in English texts (pp. 1-19). London: Pinter.

Halliday, M. A. K. (1994). Language as social semiotic. In J. Maybin (Ed.), Language and literacy in social practice (pp. 23-43). London: Open University Press.

Halliday, M. A. K., \& Matthiessen, C. M. 
(2013). Halliday's introduction to functional grammar. New York: Routledge.

Hawes, T. (2015). Thematic progression in the writing of students and professionals. Ampersand, 2, 93-100.

Hawes, T., \& Thomas, S. (1997). Problems of thematisation in student writing. RELC journal, 28(2), 35-55.

Jalilifar, A. R. (2010). The status of theme in applied linguistics articles. The Asian ESP Journal, 6(2), 7-39.

Kang, J. (2016). A functional approach to the status of theme and textual development. Theory and Practice in Language Studies, 6(5), 1053-1059.

Martin, J. R. (1992). Theme, method of development and existentiality: The price of reply. Occasional Papers in Systemic Linguistics, 6, 147-184.

Martínez, I. A. (2003). Aspects of theme in the method and discussion sections of biology journal articles in English. Journal of English for Academic Purposes, 2(2), 103-123.

Mauranen, A. (1999). What Sort of Theme is there? A translational perspective. Languages in contrast, 2(1), 57-85.

McCabe, A. M. (1999). Theme and thematic patterns in Spanish and English history texts. Doctoral dissertation, Aston University.

Mellos, V. D. (2011). Coherence in English as a second language undergraduate writing: A theme-rheme analysis. Unpublished M.A. thesis, San Diego State University.

Nguyen, T. T., \& Nguyen, T. Q. H. (2018). An Analysis of Thematic Progression Strategies in Academic IELTS Sample Essays. International Journal of Humanities, Philosophy and Language, 1(4), 85-93.

Nurdianingsih, F., \& Purnama, Y. I. (2017). The Effect of Thematic Progression Pattern Toward Students' Writing Expository Paragraph. Proceedings of the International Conference on Teacher Training and Education 2017 (pp. 288-294). Atlantis Press.

Nwogu, K. N. (1991). Structure of science popularizations: A genre-analysis approach to the schema of popularized medical texts. English for Specific Purposes, 10(2), 111-123.

Nwogu, K., \& Bloor, T. (1991). Thematic progression in professional and popular medical texts. In E. Ventola (Ed.), Functional and Systemic Linguistics: Approaches and Uses (pp. 369-384). Berlin: Mouton de Gruyter.

Paltridge, B. (2006). Discourse analysis. London: Continuum.
Pitler, E., \& Nenkova, A. (2008). Revisiting readability: A unified framework for predicting text quality. Proceedings of the 2008 Conference on Empirical Methods in Natural Language Processing (pp. 186195). https://doi.org/10.3115/1613715.1613742

Purnomo, A. (2014). Improving coherence of the students' sentences by applying thematic progression and personal blog in the sentence-based writing class. Register Journal, 7(2), 245-262.

Rakhman, A. N. (2013). An analysis of thematic progression in high school students' exposition texts. Passage, 1(1), 65-74.

Rørvik, S. (2003). Thematic progression in translation from English into Norwegian. Nordic Journal of English Studies, 2(2), 245-264.

Rosa, R. N., \& Padang, F. U. (2007). Thematic progression as a means to keep cohesion in exposition text. Jurnal Bahasa dan Seni, 8(2), 94103.

Schleppegrell, M. J. (2004). The language of schooling: A functional linguistics perspective. New Jersey: Routledge.

Soleymanzadeh, L., \& Gholami, J. (2014). Scoring argumentative essays based on thematic progression patterns and IELTS analytic scoring criteria. Procedia - Social and Behavioral Sciences, 98, 1811-1819.

Thompson, G. (2013). Introducing functional grammar. New York: Routledge.

Wang, L. (2007). Theme and rheme in the thematic organisation of text: Implications for teaching academic writing. Asian EFL Journal, 9(1), 164176.

Wei, J. (2016). Theme and thematic progression in Chinese College Students' English essays. Singapore: Springer.

Witte, S. P. (1983). Topical structure and revision: An exploratory study. College composition and communication, 34(3), 313-341.

Yang, X. (2008). Thematic Progression Analysis in Teaching Explanation Writing. English Language Teaching, 1(1), 29-33.

Yang, Y. (2015). On the patterns of thematic progression in the argumentation writing of non-English majors. US-China Foreign Language, 13(3), 222229.

Zhang, H., \& Li, X. (2009). Contrast Studies on Thematic Progression in English Newspaper and Broadcasting News Texts. Journal of XinJiang Education Institute, 25(3), 117-120. 


\title{
TÍCH DIỄN TIẾN ĐỀ NGŨ TRONG CÁC BÀI MẪU IELTS TASK 2 TRỰC TUYẾN CỦA MỘT TRANG MẠNG HỌC TIẾNG ANH
}

\author{
Nguyễn Văn Thắng ${ }^{1}$, Nguyễn Thị Minh Tâm² \\ 1. Khoa Su phạm tiếng Anh, Trương Đại học Ngoại ngũu, ĐHQGHN, \\ Phạm Văn Đồng, Cầu Giấy, Hà Nội, Việt Nam \\ 2. Khoa Ngôn ngũu và Văn hóa các nước nói tiếng Anh, Trưòng Đại học Ngoại ngũu, ĐHQGHN, \\ Phạm Văn Đồng, Cầu Giấy, Hà Nội, Việt Nam
}

Tóm tắt: Diễn tiến đề ngữ được định nghĩa là cách mà đề ngữ của một mệnh đề nhắc lại hoặc phát triển nghĩa của đề ngữ hoặc phần thuyết của mệnh đề đi trước (Paltrigde, 2006, p. 148). Dựa trên quan điểm chức năng hệ thống, McCabe (1999) đã phân chia diễn tiến đề ngữ thành năm loại, gồm có: mô hình diễn tiến tuyến tính (Simple Linear), diễn tiến cố định (Constant), diễn tiến phân đề ngữ (Split Theme), diễn tiến phân thuyết (Split Rheme), diễn tiến siêu đề phái sinh (Derived Hypertheme). Nghiên cứu này tìm hiểu sự hiện thực hoá của các hình thức diễn tiến đề ngữ khác nhau và ảnh hưởng của chúng đến chất lượng của các bài viết IELTS Task 2. Được lấy từ một trang mạng trực tuyến, ngữ liệu bao gồm 24 bài luận đã được phân tích bằng cả phương pháp định lượng và định tính. Kết quả nghiên cứu chỉ ra rằng mô hình diễn tiến tuyến tính được sử dụng nhiều nhất, theo sau đó là mô hình diễn tiến cố định, diễn tiến phân thuyết, diễn tiến phân đề ngữ và diễn tiến siêu đề phái sinh. Quá trình phân tích ngữ liệu cũng cho thấy rằng mặc dù mỗi mô hình mang lại những hiệu quả khác nhau, việc sử dụng các mô hình diễn tiến đề ngữ nói chung đã góp phần tạo nên sự mạch lạc và tính liên kết cho bài viết. Mô hình diễn tiến tuyến tính với sự liên kết mang tính chất quy chiếu đã tạo nên một văn bản được phát triển liên tục và có tính liên kết chặt chẽ trong khi mô hình diễn tiến cố định thì giữ được trọng tâm về chủ đề giữa các câu. Trong khi đó, nghiên cứu thấy được rằng mô hình diễn tiến phân thuyết và diễn tiến phân đề ngữ mang lại tính có tổ chức cho sự phát triển của văn bản, còn mô hình diễn tiến siêu đề phái sinh tạo được sự liên kết qua mối quan hệ giữa từ cấp trên (thượng danh) và từ cấp dưới (hạ danh). Một số vấn đề như sự thiếu diễn tiến đề ngữ, sự đặt sai vị trí chủ đề và sự lạm dụng của "There" và "It" ở vị trí chủ đề cũng đã được tìm thấy trong ngữ liệu nghiên cứu.

Tù khóa: diễn tiến đề ngữ, bài mẫu IELTS Task 2, chất lượng bài viết. 